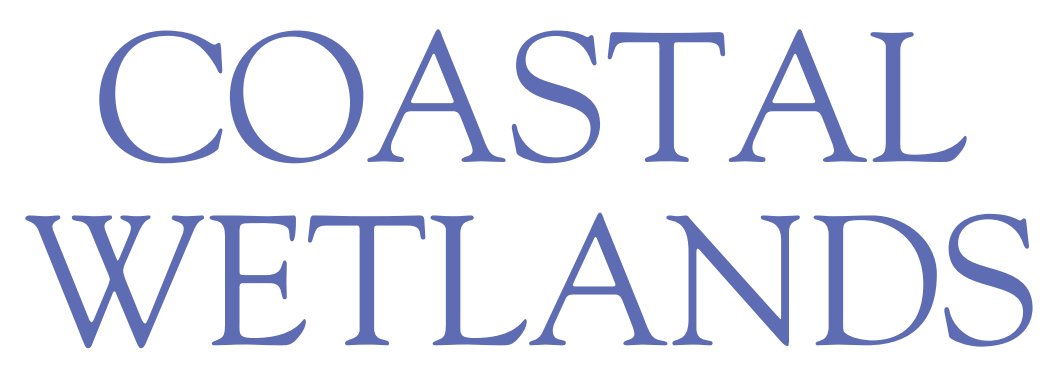

\title{
AN INTEGRATED ECOSYSTEM APPROACH
}

\section{SECOND EDITION}

Edited by

Gerardo M.E. Perillo

ERIC WOLANSKI

DONALD R. CAHOON

Charles S. Hopkinson

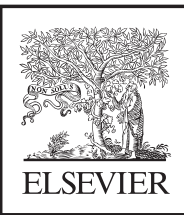




\section{Elsevier}

Radarweg 29, PO Box 211, 1000 AE Amsterdam, Netherlands

The Boulevard, Langford Lane, Kidlington, Oxford OX5 1GB, United Kingdom

50 Hampshire Street, 5th Floor, Cambridge, MA 02139, United States

Copyright () 2019 Elsevier B.V. All rights reserved. Donald R. Cahoon's contribution to the work is the work of a US Govt. employee and is in public domain.

No part of this publication may be reproduced or transmitted in any form or by any means, electronic or mechanical, including photocopying, recording, or any information storage and retrieval system, without permission in writing from the publisher. Details on how to seek permission, further information about the Publisher's permissions policies and our arrangements with organizations such as the Copyright Clearance Center and the Copyright Licensing Agency, can be found at our

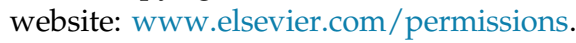

This book and the individual contributions contained in it are protected under copyright by the Publisher (other than as may be noted herein).

\section{Notices}

Knowledge and best practice in this field are constantly changing. As new research and experience broaden our understanding, changes in research methods, professional practices, or medical treatment may become necessary.

Practitioners and researchers must always rely on their own experience and knowledge in evaluating and using any information, methods, compounds, or experiments described herein. In using such information or methods they should be mindful of their own safety and the safety of others, including parties for whom they have a professional responsibility.

To the fullest extent of the law, neither the Publisher nor the authors, contributors, or editors, assume any liability for any injury and/or damage to persons or property as a matter of products liability, negligence or otherwise, or from any use or operation of any methods, products, instructions, or ideas contained in the material herein.

\section{Library of Congress Cataloging-in-Publication Data}

A catalog record for this book is available from the Library of Congress

\section{British Library Cataloguing-in-Publication Data}

A catalogue record for this book is available from the British Library

ISBN: 978-0-444-63893-9

For information on all Elsevier publications visit our website at https://www.elsevier.com/books-and-journals

\begin{tabular}{|c|c|c|}
\hline 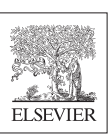 & $\underset{\substack{\text { Book Aid } \\
\text { International }}}{\text { N/2 }}$ & $\begin{array}{l}\text { Working together } \\
\text { to grow libraries in } \\
\text { developing countries }\end{array}$ \\
\hline
\end{tabular}

Publisher: Candice Janco

Acquisition Editor: Louisa Hutchins

Editorial Project Manager: Emily Thomson

Production Project Manager: Nilesh Kumar Shah

Cover Designer: Mark Rogers

Typeset by TNQ Technologies 


\section{Dedication}

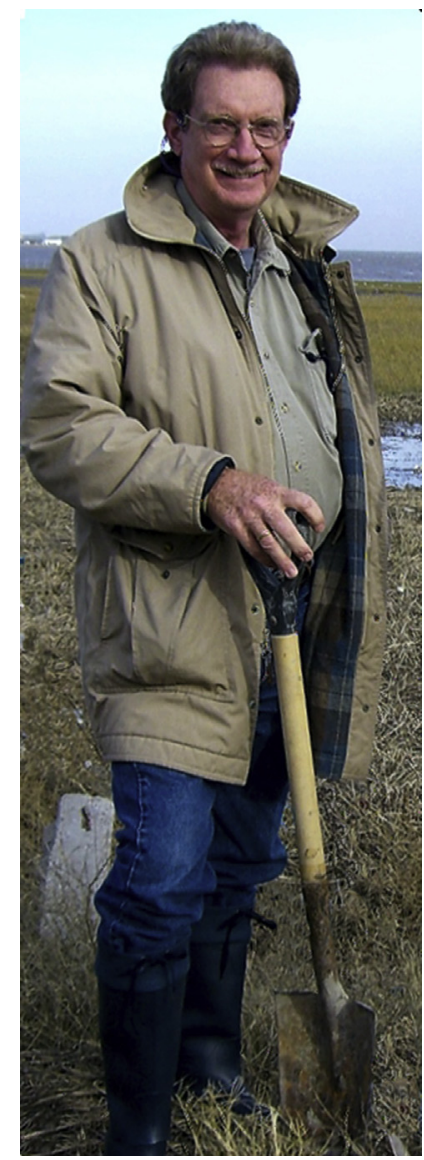

The editors wish to dedicate the present book to the memory of Dr. Mark M. Brinson, our friend, colleague, and member of the editorial team of the first edition of Coastal Wetlands: An integrated Ecosystem Approach.

Gerardo M.E. Perillo, Eric Wolanski, Donald R. Cahoon, and Charles S. Hopkinson

Dr. Mark M. Brinson retired in September 2010 with the title of Distinguished Research Professor, after more than 35 years at East Carolina University. We were looking forward to several more active years of research and professional service when he unexpectedly passed away a few months later, on January 3, 2011. In words of his dear friend and colleague, Dr. Robert Christian, we lost a thoughtful, hardworking, and creative Ecosystem Naturalist that day.

Mark devoted his research to understanding how wetlands function, unraveling the intricate relationships among the physical, chemical, and biological components of wetland ecosystems. His unique perspective made substantial contributions not only to wetland science but also to the environmental management of wetlands. Mark's work had a significant impact on the hydrogeomorphic classification of wetlands, central to the functional assessment of wetlands and mitigation procedures based on functional loss. This functional approach along with the use of reference states that one of his most significant contributions greatly changed mitigation policies and targets for restoration strategies.

Throughout his career, Mark taught numerous courses and workshops on wetland ecology within the United

States and abroad. He has edited, authored, and coauthored many publications on wetland ecology and served as a technical consultant to the US Environmental Protection Agency, US Fish and Wildlife Service, and the Smithsonian Institution. He was also President of the Society of Wetland Scientists and served on its Board of Directors for several years. In addition, Mark has received many honors and awards, including the Thomas Harriot College of Arts and Sciences Distinguished Professor Award, Lifetime Achievement Award, a National Wetlands Award for Science Research cosponsored by the Environmental Law Institute and the Environmental Protection Agency, and Fellowship of the Society of Wetland Scientists.

On a more personal note, I met Mark in 2003, when I was a graduate student at Universidad de Buenos Aires. By that time he was using a Fulbright Foreign Scholarship Award 
to aid in the development of a national wetland inventory in Argentina. I was a clumsy and unfocused student who knew little about Mark then, but working with him gave me the opportunity of a lifetime to become a wetland ecologist. Mark was one of the most respectful people I ever knew, but I could not describe Mark better than himself. As he said in his retirement essay, he did not like "being shrouded by the transparent tapestry of ego." And that was Dr. Mark Brinson, the Senior Scientist and Distinguished Professor who did not miss a single field trip to my marsh sites. He wrote my field notes, helped me out with the peat sampler, and cooked dinner.

In his retirement speech he also said "Having fun is being hardwired to your profession - half of the time you don't realize how much fun it is." From all the pictures that came to my mind since I started to write this note, I choose to share this one: Mark and his big smile standing at the marsh, playing at being my field assistant, and having fun.

Dr. Paula G Pratolongo 


\section{List of Contributors}

Kenneth F. Abraham Trent University, Peterborough, ON, Canada

Paul Adam School of Biological Earth and Environmental Science, UNSW, Sydney, NSW, Australia

S. Ahmerkamp Max Planck Institute for Marine Microbiology, Bremen, Germany

Rebecca J. Aspden Scottish Oceans Institute, School of Biology, University of St Andrews, Fife, Scotland

Andrew H. Baldwin Department of Environmental Science and Technology, University of Maryland, College Park, MD, United States

Donald M. Baltz Department of Oceanography and Coastal Sciences, Louisiana State University, Baton Rouge, LA, United States

Edward B. Barbier Department of Economics, Colorado State University, Fort Collins, Colorado, United States

Aat Barendregt Utrecht University, Utrecht, The Netherlands

Kevin S. Black Partrac, Glasgow, Scotland

Laurence A. Boorman L A B Coastal, Cambridgeshire, United Kingdom

Mark M. Brinson

Stephen W. Broome Department of Crop and Soil Sciences, North Carolina State University, Raleigh, NC, United States

Benjamin M. Brown Charles Darwin University, Research Institute for Environment and Livelihoods (RIEL), Darwin, NT, Australia

Michael R. Burchell Department of Biological and Agricultural Engineering, North Carolina State University, Raleigh, NC, United States
Donald R. Cahoon United States Geological Survey, Patuxent Wildlife Research Center, Laurel, MD, United States

L. Carniello Department of Civil, Environmental and Architectural Engineering, University of Padua, Padova, Italy

Edward Castañeda-Moya Southeast Environmental Research Center, Florida International University, Miami, FL, United States

Elizabeth Christie Cambridge Coastal Research Unit, Department of Geography, University of Cambridge, Cambridge, United Kingdom

P.L.M. Cook Water Studies Centre, Monash University, Clayton, VIC, Australia

Christopher B. Craft School of Public and Environmental Affairs, Indiana University, Bloomington, IN, United States

Carolyn A. Currin NOAA, National Centers for Coastal Ocean Science, Beaufort Lab, Beaufort, NC, United States

Andrea D'Alpaos Department of Geosciences, University of Padova, PD, Italy

L. D'Alpaos Department of Civil, Environmental and Architectural Engineering, University of Padua, Padova, Italy

Stephen Davis Everglades Foundation, Palmetto Bay, FL, United States

Dirk de Beer Max Planck Institute for Marine Microbiology, Bremen, Germany

A. Defina Department of Civil, Environmental and Architectural Engineering, University of Padua, Padova, Italy

Joanna C. Ellison Discipline of Geography and Spatial Sciences, School of Technology, Environments and Design, University of Tasmania, Launceston, TAS, Australia

\footnotetext{
${ }^{\dagger}$ Deceased.
} 
Laura L. Flynn Coastal Resources Group, Inc., Venice, FL, United States

Irene Fortune Scottish Oceans Institute, School of Biology, University of St Andrews, Fife, Scotland

Jon French Coastal and Estuarine Research Unit, UCL Department of Geography, University College London, Gower Street, London, United Kingdom

Shu Gao State Key Laboratory for Estuarine and Coastal Research, East China Normal University, Shanghai, China

Christopher Haight New York City Department of Parks \& Recreation, New York, NY, United States

Richard S. Hammerschlag United States Geological Survey, Patuxent Wildlife Research Center, Laurel, MD, United States

Ellen Kracauer Hartig New York City Department of Parks \& Recreation, New York, NY, United States

Marianne Holmer Department of Biology, University of Southern Denmark, Odense, Denmark

Charles S. Hopkinson Department of Marine Sciences, University of Georgia, Athens, GA, United States

Robert L. Jefferies ${ }^{\dagger}$

S.B. Joye Department of Marine Sciences, University of Georgia, Athens, GA, United States

Jeffrey J. Kelleway Department of Environmental Sciences, Macquarie University, Sydney, NSW, Australia

Jason R. Kirby Liverpool John Moores University, School of Natural Sciences \& Psychology, Liverpool, United Kingdom

Stefano Lanzoni Department of Civil, Environmental, and Architectural Engineering, University of Padova, PD, Italy

Marit Larson New York City Department of Parks \& Recreation, New York, NY, United States

${ }^{\dagger}$ Deceased.
Paul S. Lavery School of Science \& Centre for Marine Ecosystems Research, Edith Cowan University, Joondalup, WA, Australia; Centro de Estudios Avanzados de Blanes, Consejo Superior de Investigaciones Científicas, Blanes, Spain

Nicoletta Leonardi University of Liverpool, School of Environmental Sciences, Department of Geography and Planning, Liverpool, United Kingdom

Roy R. Lewis III Coastal Resources Group, Inc., Salt Springs, FL, United States

Catherine Lovelock The School of Biological Sciences, The University of Queensland, St Lucia, QLD, Australia; Global Change Institute, The University of Queensland, St Lucia, QLD, Australia

Marco Marani Department of Civil, Environmental, and Architectural Engineering, University of Padova, PD, Italy

I. Peter Martini School of Environmental Sciences, University of Guelph, Guelph, ON, Canada

Karen L. McKee U.S. Geological Survey, Wetland and Aquatic Research Center, Lafayette, LA, United States

J. Patrick Megonigal Smithsonian Environmental Research Center, Edgewater, MD, United States

Stephen Midway Department of Oceanography and Coastal Sciences, Louisiana State University, Baton Rouge, LA, United States

Iris Möller Cambridge Coastal Research Unit, Department of Geography, University of Cambridge, Cambridge, United Kingdom

R.I. Guy Morrison National Wildlife Research Centre, Environment and Climate Change Canada, Ottawa, ON, Canada

Scott C. Neubauer Department of Biology, Virginia Commonwealth University, Richmond, VA, United States

David M. Paterson Scottish Oceans Institute, School of Biology, University of St Andrews, Fife, Scotland 
Gerardo M.E. Perillo Instituto Argentino de Oceanografía (CONICET - UNS), Bahía Blanca, Argentina; Departamento de Geología, Universidad Nacional del Sur, Bahía Blanca, Argentina

Maria Cintia Piccolo Instituto Argentino de Oceanografia - Universidad Nacional del Sur, Bahia Blanca, Buenos Aires, Argentina

Andrew Plater University of Liverpool, School of Environmental Sciences, Department of Geography and Planning, Liverpool, United Kingdom

Paula Pratolongo Universidad Nacional del Sur, Dto. de Biología Bioquímica y Farmacia CONICET, Instituto Argentino de Oceanografía, Bahía Blanca, Argentina

Andrea Rinaldo Department of Civil, Environmental, and Architectural Engineering, University of Padova, PD, Italy; Laboratory of Ecohydrology, Ecole Polytechnique Fèdèrale Lausanne, Lausanne, Switzerland

Victor H. Rivera-Monroy Department of Oceanography and Coastal Sciences, College of the Coast and the Environment, Louisiana State University, Baton Rouge, LA, United States

Kerrylee Rogers Geoquest, University of Wollongong, Wollongong, NSW, Australia

Andre S. Rovai Department of Oceanography and Coastal Sciences, College of the Coast and the Environment, Louisiana State University, Baton Rouge, LA, United States; Programa de Pós-Graduação em Oceanografia, Universidade Federal de Santa Catarina, Florianópolis, Brazil

Neil Saintilan Department of Environmental Sciences, Macquarie University, Sydney, NSW, Australia

Charles E. Sasser Department of Oceanography and Coastal Sciences, Louisiana State University, Baton Rouge, LA, United States
C.A. Schutte Louisiana Universities Marine Consortium (LUMCON), Chauvin, LA, United States

M. Seidel Institute for Chemistry and Biology of the Marine Environment (ICBM), University of Oldenburg, Oldenburg, Germany

Liudmila A. Sergienko Department of Botany and Plant Physiology, Petrozavodsk State University, Petrozavodsk, Russia

Oscar Serrano School of Science \& Centre for Marine Ecosystems Research, Edith Cowan University, Joondalup, WA, Australia

Daniel O. Suman Rosenstiel School of Marine and Atmospheric Science, University of Miami, Miami, FL, United States

Rebecca K. Swadek New York City Department of Parks \& Recreation, New York, NY, United States

Craig Tobias University of Connecticut, Groton, CT, United States

Robert R. Twilley Department of Oceanography and Coastal Sciences, College of the Coast and the Environment, Louisiana State University, Baton Rouge, LA, United States

Jenneke M. Visser Institute for Coastal and Water Research, and School of Geosciences, University of Louisiana at Lafayette, Lafayette, LA, United States

Dennis F. Whigham Smithsonian Environmental Research Center, Edgewater, MD, United States

Eric Wolanski TropWATER and College of Science and Engineering, James Cook University, Townsville, QLD, Australia; Australian Institute of Marine Science, Townsville, QLD, Australia

Colin D. Woodroffe School of Earth and Environmental Sciences, University of Wollongong, Wollongong, NSW, Australia

C.S. Wu Max Planck Institute for Marine Microbiology, Bremen, Germany 


\section{Preface to the First Edition}

Why coastal wetlands? What is so important about them that a whole book is required to try to review and explain their large variety of properties? Of all the coastal habitats, wetlands are the least depicted in the tourist brochures because they lack those paradisiacal long, white sandy beaches backed by palm trees or expensive resort hotels close to transparent blue waters. In fact, most coastal wetlands are quite muddy and are more likely to be inhabited by crabs and worms than by charismatic fish, birds and mammals. Hence, most inhabitants of our world either have never thought about coastal wetlands or may consider them a nuisance, not realizing that their seafood dinner likely had its origin as a detrital food web in a salt marsh or mangrove swamp. Bahía Blanca (Argentina) inhabitants are a classical example: a city of over 300,000 people living within $10 \mathrm{~km}$ of a $2300-\mathrm{km}^{2}$ wetland, the largest of Argentina, but fewer than $40 \%$ have any idea that they are so close to the sea and a short distance of places that are globally unique (Perillo and Iribarne, 2003, in Chapter 6).

Similarly, there are many other coastlines dominated by wetlands, yet they are only seen as areas to exploit in an unsustainable fashion. For example, mangroves have served local communities for generations in many Asian tropical countries for harvesting wood and fish in contrast to their wholesale replacement for rice cultivation and shrimp farming.

Even though management guidelines have been available for decades, the negative consequences of uninformed exploitation have resulted in poor or even total lack of management criteria by most governments at all levels. Even local stakeholders fail to act in their own best interest without consideration of the ecosystem goods and services that the nearby wetlands provide.

Coastal wetlands best develop along passive-margin coasts with low-gradient coastal plains and wide continental shelves. The combination of low hydraulic energy and gentle slope provides an ideal setting for the wetland development. Also passive margins are less prone to receive large episodic events like tsunamis. Tsunamis and storm surges, in particular, are major coast modifiers, but when they act on low coasts their effects are more far reaching than they are on higher relief coasts. For a wetland to form, there is a need for a particular geomorphological setting such as an embayment or estuary providing a relatively low-energy environment favoring sediment settling, deposition and preservation. However, that is only the beginning of a large and complex "life" where many geological (i.e., sediment supply, geological setting and isostasy), physical (i.e., oceanographic, atmospheric, fluvial, groundwater processes and sea level changes), chemical (i.e., nutrients, pollutants), biological (i.e., intervening flora and fauna), and anthropic factors play a wide spectra of roles. Coastal wetlands are areas that have combined physical sources and biological processes to develop structure that continues to take advantage of natural energy inputs. 
This book has been planned to address in an integrated way all these processes and their consequences on the characterization and evolution of coastal wetlands. It aims to provide an integrated perspective on coastal wetlands as ecosystems for the public, engineers, scientists and resources managers. It is only after acquiring this perspective that scientists can confidently propose ecohydrologic solutions for managing these environments in an ecologically sustainable way. This is but one small step toward encouraging humanity to look beyond purely technological, and often failed, solutions to complex environmental problems.

This is done by focusing on the principal components considering the full range of environments from freshwater to subtidal and from polar to tropical systems. The book has been divided into seven parts starting from a synthesis chapter that integrates the whole book. Part I covers, in three chapters, the general description of the wetlands structured according to broad climatic regions and introduces the most important physical processes that are common to all coastal wetlands including some geomorphologic and modeling principles. Part II are specific to each particular type of wetland (tidal flats, marshes and seagrasses, and mangroves). Within each part (Parts III to $\mathrm{V}$ ), there are chapters dealing with their particular geomorphology, sedimentology, biology and biogeochemistry. Finally Parts VI and VII provide insight into the restoration and management and sustainability and landscape dynamics.

As editors, our work was greatly facilitated by the tremendous cooperation and enthusiasm from each of the authors to complete this process that began mid 2006. Each author, an authority in his or her specialty, was specifically invited to write a review chapter. Therefore, the challenges were much larger than in the case of typical contributed articles. But the reward, we think, is much more beneficial for the student, professor, or researcher employing this book for his or her particular interest. Readers will not only be able to find a specific topic but will find related information to complement and enhance the understanding of the topic.

We are in debt to the more than 50 reviewers (most of them are not authors in the book) who have agreed and provided graciously and unselfishly their valuable time. Some took on the responsibility of two chapters, and their efforts are rewarded with improvements of each contribution. In many cases, reviewers gave us interesting ideas that helped in the general structure of the book. A list of the reviewers is provided.

We also thank Elsevier Science and the various Publishing Editors who were in charge of our book along the period since we first proposed our idea to the final result that you are reading now. First of all to Kristien van Lunen who first believed that our proposal was realizable and then to the important contributions and patience of Jennifer Hele, and also to Pauline Riebeek, Linda Versteeg and lastly Sara Pratt. Stalin Viswanathan did an excellent job copyediting the whole book.

Gerardo M.E. Perillo Eric Wolanski

Donald R. Cahoon Mark M. Brinson July, 2008

This document is based on work partially supported by the U.S. National Science Foundation under Grants No. BSR-870233306, DEB-9211772, DEB-9411974, DEB-0080381 and DEB-0621014 and to SCOR under Grant No. OCE-0608600. Any opinions, findings, and conclusions or recommendations expressed in this material are those of the authors and do not necessarily reflect the views of the U.S. National Science Foundation (NSF). 


\section{Preface to the Second Edition}

As we wrote this preface, we realized that exactly 10 years have passed since the time we wrote the original preface for the first edition. Three and half years ago, Elsevier-with a surprising mail by Candice Janco-invited us to look into the possibility of a second edition. Although initially the thought of getting back into all the effort that editing a book of these characteristics demands seemed an unhealthy adventure, all of us actually jumped right in with the idea. Unfortunately, as we present in the dedicatory, our good friend Mark Brinson passed away in the period between both editions. However, Chuck Hopkinson has been brave enough to come on board playing a major role in the outcome of the book.

All the comments given in the original preface are as true today as they were then. Unfortunately, many management issues and complex situations that coastal wetlands were suffering are still present today and, graver, they have become worse. Therefore, they will not be repeated here.

In this sense, to the original structure of the book, we added new chapters pointing out specifically new views of coastal wetlands management and valuation. Nevertheless, each chapter was significantly improved and updated to reflect on the new advances achieved by the wetland community in the last 10 years.
Many of the original lead authors from the first edition gladly accepted the challenge to get back to their old notes and redo them for the new edition. A few could not commit themselves to the task for various reasons. In the cases where it was possible, we found new adventurers who were willing to take the "relay baton" and write a completely new chapter on the subject.

In all cases, we must remember, authors were asked to make a thorough review on a specific subject rather than describe their own personal work. However, we relied on the outstanding capabilities and worldwide recognition each of the lead authors brought to the book, accompanied by no lesser coauthors.

Again, we could not have presented a book of this level of quality without the unselfish input of over 50 reviewers. They were essential in providing us with their expertise for those chapters in which we may not be as confident as them. A book is as good as its authors, and also it is improved by the quality of its reviewers. We cannot thank enough each and every one of them for their time and support.

Finally, again we cannot thank enough the original invitation of Candice Jancowho left us not only for another position within Elsevier almost at the beginning of the project but also in the very capable 
hands, the amenability, and the good humor of Emily Joy Grace Thomson. She helped us through all the steps-even those initial failures-with quick responses and many times going out of her way to look for solutions, some almost impossible. We also want to thank the invaluable contributions by Nilesh Shah and Rajesh Manohar for his capable and professional work in doing the copyediting of the book.

Gerardo M.E. Perillo

Eric Wolanski

Donald R. Cahoon

Charles S. Hopkinson

July 2018 


\section{List of Reviewers}

9 anonymous

Iris Anderson

Donald R. Cahoon

John Callaway

Giovanni Coco

Steve Davis

John Day

Luiz Drude de Lacerda

Steven Dundas

Carl Fitz

Duncan Fitzgerald

Shu Gao

John Grant

Charles S. Hopkinson

Chris Kennedy

Mary Kentula

Ken W. Krauss

Megan LaPeyre
Christopher Madden

Marco Marani

Beth Middleton

Kathleen Onorevole

Michael Osland

Morten Pejrup

Steven Pennings

Gerardo M. E. Perillo

Stephen Polasky

Charles Roman

Rochelle Seitz

Tom Spencer

Craig Tobias

Raymond Torres

Reginald Uncles

Bethney Ward

Eric Wolanski 